\title{
Colonization of Potato Plants after Aerial Infection by Colletotrichum coccodes, Causal Agent of Potato Black Dot
}

\author{
N. Nitzan, Department of Plant Pathology, Washington State University, Pullman 99164-6430; M. Evans, Depart- \\ ment of Statistics, Washington State University, Pullman 99164-6430; and D. A. Johnson, Department of Plant Pa- \\ thology, Washington State University, Pullman 99164-6430
}

\begin{abstract}
Nitzan, N., Evans, M., and Johnson, D. A. 2006. Colonization of potato plants after aerial infection by Colletotrichum coccodes, causal agent of potato black dot. Plant Dis. 90:999-1003.

Colonization of potato plants by Colletotrichum coccodes after artificial inoculation of stems was modeled in relation to the severity of chlorosis and necrosis on foliage using logistic regression. C. coccodes internally colonized the stems up to $24 \mathrm{~cm}$ above the inoculation court (mean of $11.3 \pm 7.7 \mathrm{~cm}$ and $14.1 \pm 9.3 \mathrm{~cm}$ in 2003 and 2004, respectively), and completely colonized the stem below the inoculation court including the roots (mean of $13.2 \pm 3.1 \mathrm{~cm}$ and $12 \pm 2.3 \mathrm{~cm}$ in 2003 and 2004, respectively). C. coccodes grew significantly faster from the inoculation court toward the roots, stolons, and tubers than toward the plant apex. Internal stem colonization was restricted before senescence but rapidly increased as the plants started to senescence, suggesting that physiological events associated with plant senescence activated fungal growth and plant colonization. The results showed no relationship between $C$. coccodes growth and plant colonization and the development of chlorosis and necrosis severity of leaves. The severity of chlorosis and necrosis on foliage in this study was the outcome of natural plant senescence, and was not caused by the fungal colonization. Therefore, chlorosis and necrosis severity is an inaccurate tool to diagnose infection in potato by $C$. coccodes and does not indicate the presence or amount of $C$. coccodes in potato plants. Disease assessment for $C$. coccodes in potato plants should not rely on severity of chlorosis and necrosis. Black dot assessment should be carried out by isolation and quantification of the fungus from stem and root tissues or by polymerase chain reaction techniques before plant senescence.
\end{abstract}

Potato black dot, caused by Colletotrichum coccodes (Wallr.) S.J. Hughes (syn. C. atramentarium (Berk. \& Br. Taub)), is characterized by small black sclerotia on the roots, stems, stolons, and progeny tubers of infected plants $(4,8,29)$. Black dot is common in most potato growing areas in the world $(1,5,6,17,20)$ and may cause up to $30 \%$ yield reduction on susceptible cultivars $(13,21,26,29)$.

In the field, infection of potato plants by $C$. coccodes may be associated with soilborne, tuber-borne, and airborne inoculum, either solely or jointly in different combinations $(12,13,18,29)$. In the Columbia Basin of central Washington, C. coccodes has been isolated relatively early in the growing season from below- and aboveground potato stems and from a high proportion of plants by midseason $(13,14)$. Disease symptoms often do not become evident until late in the growing season, and numerous sclerotia develop on plant parts as plants senesce and die $(13,18)$. Latent infections by $C$. coccodes in potato

Corresponding author: N. Nitzan

E-mail: nun2@psu.edu

Accepted for publication 6 March 2006.

DOI: 10.1094/PD-90-0999

(C) 2006 The American Phytopathological Society stems were suggested in an earlier study to explain the early infections and later expression of sclerotia (13).

The consensus from the literature is that soil-borne and tuber-borne inocula are the main inoculum sources for black dot development in potato plants. However, airborne infection may be an important contributor to the initiation and development of the disease. The frequency of black dot development from aerial infection in potato plants under field conditions is not documented. In the Pacific Northwest and other regions with similar semiarid conditions, sandstorms and sprinkler irrigation systems are common. Therefore, a high potential for foliar infection of potato plants is present, as sandstorms are capable of wounding potato foliage, while sprinkler irrigation disseminates conidia and sclerotia via splashing and contributes the requirement of high relative humidity for inoculum germination and infection $(2,13)$.

The effect of aerial infection by C. coccodes on black dot development was tested in field and greenhouse trials in Idaho and Washington State $(12,13,18)$. The foliage of Russet Burbank potato plants was sandblasted and immediately spray-inoculated with a conidial suspension of $C$. coccodes. The inoculated plants developed foliar chlorosis, necrosis, and dark brown to black lesions on leaves, petioles, and stems $(12,13,18)$. The results of the field trials in
Idaho indicated a significant yield reduction of $6.5 \mathrm{t} / \mathrm{ha}$ (about $10 \%$ in relation to contemporary average yield) (18). Results of the greenhouse trials in Washington State recorded a significant reduction in total yield (19 to 32\%) and a reduction of mean tuber weight (29 to 43\%) (12). Results of the field trials in Washington State recorded a significant reduction in total tuber weight by 7,12 , and $11 \%$ and a significant reduction of yearly U.S. No. 1 potatoes weight by 12,18 , and $16 \%$ over 3 years (12).

Little information is available on the colonization process of potato stems after aerial infection by $C$. coccodes and the relationship between colonization and development of the foliar symptoms of chlorosis and necrosis. Such knowledge would be helpful in understanding the development of $C$. coccodes in the field, and in developing disease management strategies for black dot. The present study tested the hypothesis that $C$. coccodes is capable of infecting potato plants via stems and spread internally up and down the stem. The objectives of the study were: (i) to determine the relationship between chlorosis and necrosis severity on potato foliage and $C$. coccodes colonization of the plants; and (ii) to determine the colonization pattern of $C$. coccodes originating from stem inoculation and construct a colonization and disease progress model.

\section{MATERIALS AND METHODS}

C. coccodes isolates. The monoconidial isolates 1018 (origin: potato, Washington State, 1990) and 2044 (origin: potato, Washington State, 1997) were used. The isolates were previously assigned to the North American vegetative compatibility groups NA-VCG1 and NA-VCG2, respectively (19), indicating that they were from different genetic backgrounds. The isolates were subcultured onto $1 \%$ potato dextrose agar (PDA: $10 \mathrm{~g}$ Difco PDA, $15 \mathrm{~g}$ Bacto agar, $0.1 \mathrm{~g}$ streptomycin sulfate, and 975 $\mathrm{ml}$ distilled water), incubated in the dark at $25^{\circ} \mathrm{C}$ for 7 days, and maintained at $4^{\circ} \mathrm{C}$ until use.

Plant material. Disease free, nuclear potato tubers of the C. coccodessusceptible cultivar Russet Burbank were used. Tuber pieces (24 g average) were cut from surface-sterilized tubers $(1 \% \mathrm{NaClO}$ for $10 \mathrm{~min}$ ) and were stored at $10^{\circ} \mathrm{C}$ for 48 $\mathrm{h}$ to allow partial wound healing. A total of 
90 plants were prepared (30 per isolate including noninoculated control plants) by planting one tuber piece per pot in 3-liter pots $(16 \mathrm{~cm}$ diameter by $18 \mathrm{~cm}$ height $)$ in the middle of the pot, about $1 \mathrm{~cm}$ below the soil surface. Sunshine LC1 potting mix (Sun-Gro Horticulture Distributor Inc., Bellevue, WA) was used. Twelve grams of Osmocote fertilizer (16-16-16 NPK) were added to the soil at planting. The pots were placed in the greenhouse $\left(20^{\circ} \mathrm{C}, 16 \mathrm{~h}\right.$ light), and the plants were allowed to develop until they reached an average height of $20 \mathrm{~cm}$ (about 6 weeks).

Preparation of inoculum. The isolates were cultured on $1 \%$ PDA in $9-\mathrm{cm}$ petri plates for 7 days at $25^{\circ} \mathrm{C}$ in the dark. Immediately after incubation, the conidia were harvested with $3 \mathrm{ml}$ of sterile distilled water by scraping the conidia from the agar surface and filtering through four layers of autoclaved cheesecloth. The conidia suspensions were adjusted to a final concentration of $1.3 \times 10^{5}$ conidia per ml using a hemacytometer.

Inoculation of plants. Forty-five day old potato plants that were grown in the greenhouse were injured in the middle of the stem, halfway between the soil surface and the plant apex, with a sterile scalpel. The epidermis tissue was carefully peeled off to form a $5 \times 5 \mathrm{~mm}$ wound, which served as the inoculation court. A sterile filter paper $(1 \times 1 \mathrm{~cm})$ amended with $50 \mu \mathrm{l}$ of conidial suspension was placed on the wound. The conidial suspension was absorbed by the filter paper to retain the inoculum at the inoculation court. The filter paper was left attached to the plant. Immediately after inoculation, the plants were transferred to a mist chamber for $24 \mathrm{~h}$, and were water-sprayed for $1 \mathrm{~min}$ every $10 \mathrm{~min}$ (6 sprays per hour) with two atomizers (Herrmidifier Co. Inc., Model 707 TW; Lancaster, PA). After the 24-h wetting period, the sterile filter paper amended with the conidial suspension was removed, and the plants were transferred to the greenhouse and arranged in a completely randomized design structure (CRD). The entire inoculation process, from wounding until plants were transferred into the mist chambers, ranged between 30 to $60 \mathrm{~s}$ per plant. The temperature during the wetting period was $20^{\circ} \mathrm{C}$. Sterile distilled water was used for noninoculated control plants. The $C$. coccodes isolates were used separately, and coinoculations were not performed.

In 2003, inoculations with both isolates were carried out on 2 September. In 2004, inoculation with isolate 1018 was conducted on 15 June, and with isolate 2044 on 19 June. Temperatures during the trials were $19 \pm 5.1^{\circ} \mathrm{C}$ and $23 \pm 3.4^{\circ} \mathrm{C}$ in 2003 and 2004, respectively.

Severity of chlorosis and necrosis. The amount of chlorosis and necrosis, due to either disease development or natural plant senescence, was assessed using a visual scale from 0 to 6 . Plant stems were divided equally into three sections (lower, middle, and apex) to facilitate the assessment. The scale was as follows: $0=$ green, healthy appearing plant, absence of chlorosis and necrosis; 1 = moderate chlorosis and flaccid, yellow lower leaves, the middle leaves turgid and mildly chlorotic, and the apex with green leaves; 2 = lower leaves flaccid with severe chlorosis and orange/brownish discoloration, and necrosis on the tips of the leaflets, moderate chlorosis on the middle leaves, and the plant apex with mild chlorosis; 3 = lower leaves with necrosis, all middle leaves with moderate chlorosis and 10 to $30 \%$ of them with necrosis, the plant apex with moderate chlorosis; $4=$ lower and middle leaves with necrosis or fallen off the plant, and the plant apex with severe chlorosis; $5=$ lower and middle leaves with necrosis or fallen off the plant, the plant apex flaccid with severe chlorosis, and the stem soft with dark orange discoloration; $6=$ dried plants or plants left in the pots to dry on the greenhouse bench for 10 to 14 days until sclerotia were formed. The beginning of plant senescence was considered when symptoms reached category 3 , in general, 100 days after planting for long-season potatoes such as Russet Burbank.

Plant sampling and evaluation of infection. Ninety plants were grown for research purposes in 2003 and again in 2004. The plants were randomly assigned to three groups with 30 plants per group: 1) plants inoculated with isolate $1018 ; 2$ ) plants inoculated with isolate 2044; and 3) noninoculated plants as the control. Approximately five plants were randomly selected from each treatment group according to the symptom categories of chlorosis and necrosis development, and the time of their expression. In 2003, chlorosis and necrosis developed rapidly. Therefore, plants with symptom categories 1,2 , and 3 were sampled 49 days after inoculation (DAI), or 94 days after planting; and plants with symptom categories 4,5 , and 6 were sampled 64, 77, and 90 DAI, respectively, or 109,122 , and 135 days after planting, respectively. In 2004, plants inoculated with isolate 1018 and control plants were sampled $28,42,57,65,80$, and $87 \mathrm{DAI}$, or 73, 87, 102, 110, 125, and 132 days after planting; and plants inoculated with isolate 2044 were sampled $24,38,53,61,76$, and 83 DAI, or $69,83,98,106,121$, and 128 days after planting for symptom categories $1,2,3,4,5$, and 6 , respectively.

Following harvest, leaves were excised and stems were disinfested (1\% $\mathrm{NaClO}$ for $10 \mathrm{~min})$. The stems were divided into three sections. The first stem section was the inoculation court (the $5 \times 5 \mathrm{~mm}$ segment where inoculation was conducted) that was used as a positive control for infection. The second and third stem sections were the upper section (above the inoculation court) and the lower section (below the inocula- tion court), respectively. The upper and lower stem sections were dissected entirely into $1-\mathrm{cm}$ segments, progressing by $1 \mathrm{~cm}$ from the inoculation court. The roots were not sampled. To prevent potential contamination of healthy stem sections, the scalpel was sterilized between cuttings. The stem segments were placed onto modified PDA (1 g Difco PDA, 20 g Bacto agar, $0.2 \mathrm{~g}$ streptomycin sulfate, $5 \mathrm{ml}$ ethanol, and 975 $\mathrm{ml}$ distilled water) and were incubated for 10 days at $25^{\circ} \mathrm{C}$ in the dark. The inoculation court was also placed on modified PDA to confirm infection. On the last five plants, which were allowed to die and dry (symptom category 6), sclerotia were visible without magnification, and the distance from inoculation court that sclerotia were formed was directly measured with a ruler.

Statistical analysis. The fungal colonization of stems was recorded as a binary outcome with $1=$ colonized stem segment, and $0=$ noncolonized stem segment. Colonization was the response of interest, and since it was recorded as a binary outcome, a multiple linear logistic regression analysis was used to assess its relationship to the predictor variables (11). Proc Logistic in SAS (SAS 9.1; SAS Institute, Cary, NC) was used to compute the coefficients of the logistic regression model, which included the following linear predictors: isolate type (1018 or 2044), chlorosis and necrosis severity (a scale of 1 to 6 ), distance $(\mathrm{cm})$ from the inoculation court, and direction of fungal colonization (above or below the inoculation court). Fungal colonization was calculated as infection probability $(\mathrm{Pi})$, which indicated the odds of a stem segment to be colonized by the fungus at a certain distance above or below the inoculation court. Pi was calculated as the logarithm of infected segments $(P)$ divided by noninfected segments $(1-P)$, or $\mathrm{Pi}=\log$ $(P / 1-P)$. Because the type of isolate and the direction of fungal colonization in the stem were two-level quantitative predictors, these variables were dummy coded: 0 if isolate $=2044$ and 1 if isolate $=1018$; and $0=$ direction down from inoculation court, and 1 = direction up from inoculation court. All inferences were based on a level of significance at $P=0.05$. Differences in the severity of chlorosis and necrosis and the time of their expression between inoculated and noninoculated control plants were tested using student's $t$ test $(\alpha=0.05)$.

\section{RESULTS}

C. coccodes was isolated from 47 of 60 (78\%), and 52 of $60(87 \%)$ potato plants that were stem-inoculated in 2003 and 2004, respectively. The fungus did not infect control plants and was not isolated from the controls. C. coccodes colonized the stems of infected plants to a maximum height of $24 \mathrm{~cm}$ above the inoculation court (mean \pm standard deviation: $11.3 \pm$ $7.7 \mathrm{~cm}$ and $14.1 \pm 9.3 \mathrm{~cm}$ in 2003 and 
2004, respectively). The lower stem sections were completely colonized both years (mean \pm standard deviation: $13.2 \pm$ $3.1 \mathrm{~cm}$ and $12.0 \pm 2.3 \mathrm{~cm}$ in 2003 and 2004, respectively). On the dry plants (chlorosis and necrosis severity category 6), sclerotia were observed on both stems and roots of inoculated plants.

$C$. coccodes was only isolated from inoculated stems; therefore, the logistic regression analysis was only conducted using the data of the inoculated plants. The logistic regression analysis indicated that isolate 2044 colonized the stems significantly $(P=0.0016)$ faster than isolate 1018 in 2003, but not in $2004(P=0.7765)$. Isolates 1018 and 2044 had similar patterns of colonization above and below the inoculation court, and their results are presented jointly (Figs. 1 to 4 ). In both years, fungal colonization significantly $(P$ $<0.0001)$ decreased as the distance away from the inoculation court increased. Fungal colonization was also significantly $(P<$ $0.0001)$ greater below than above the inoculation court both years (Figs. 1 to 4 ).

The severity of chlorosis and necrosis and the time of their expression did not vary $(P>0.05)$ between inoculated and noninoculated control plants (Fig. 5). However, fungal colonization had a curvilinear relationship with the severity of chlorosis and necrosis both years. In 2003, the curvilinear relationship had significant $(P<0.0001)$ linear and quadratic regression coefficients. Therefore, the fungal colonization of the upper stem sections declined from 0.8 to 0.4 as the severity of chlorosis and necrosis progressed from category 1 to 3 (Fig. 1). The colonization of the upper stem sections in 2003 increased to 0.9 as the severity of chlorosis and necrosis exceeded category 3 (plant senescence). The increased colonization is indicated by the upward curvature of the regression surface (Fig. 1). In 2004, the fungal colonization again possessed a curvilinear relationship with the severity of chlorosis and necrosis. However, in 2004, only the linear regression coefficient was significant $(P<0.0001)$, whereas the quadratic coefficient was not significant, but notable $(P=0.0513)$. In 2004, the fungal colonization of the upper stem sections

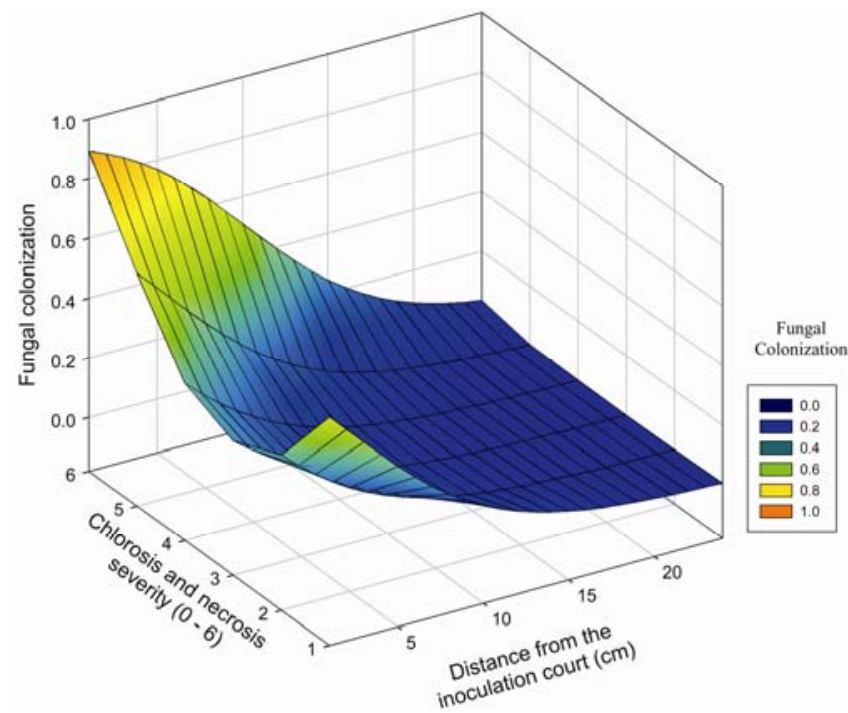

Fig. 1. Relationship among fungal colonization of the upper stem section, chlorosis and necrosis severity, and distance from the inoculation court in potato plants infected with Colletotrichum coccodes isolates 1018 and 2044 in 2003.

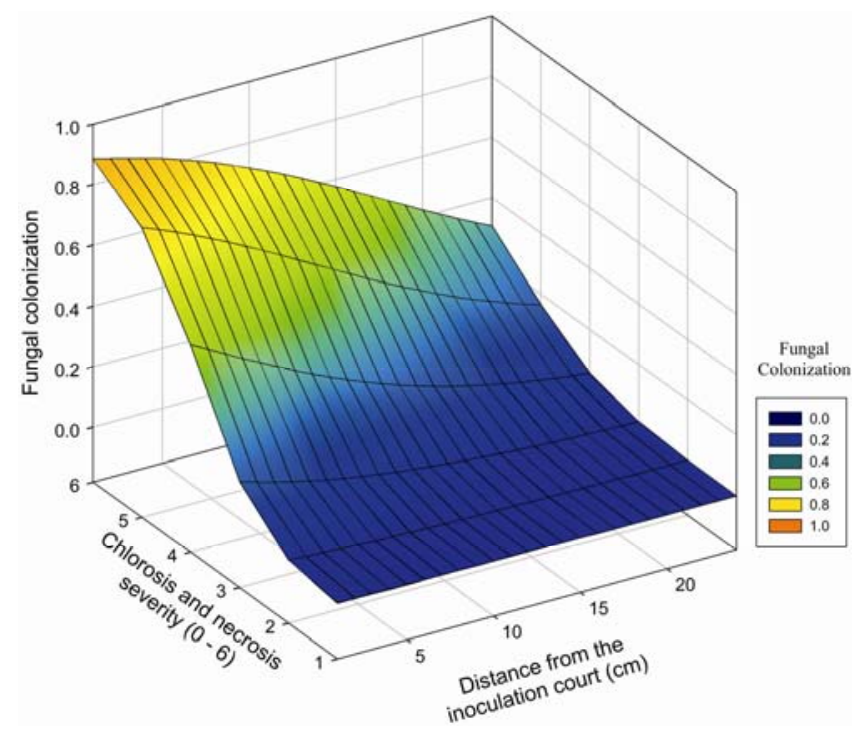

Fig. 2. Relationship among fungal colonization of the upper stem section, chlorosis and necrosis severity, and distance from the inoculation court in potato plants infected with Colletotrichum coccodes isolates 1018 and 2044 in 2004.

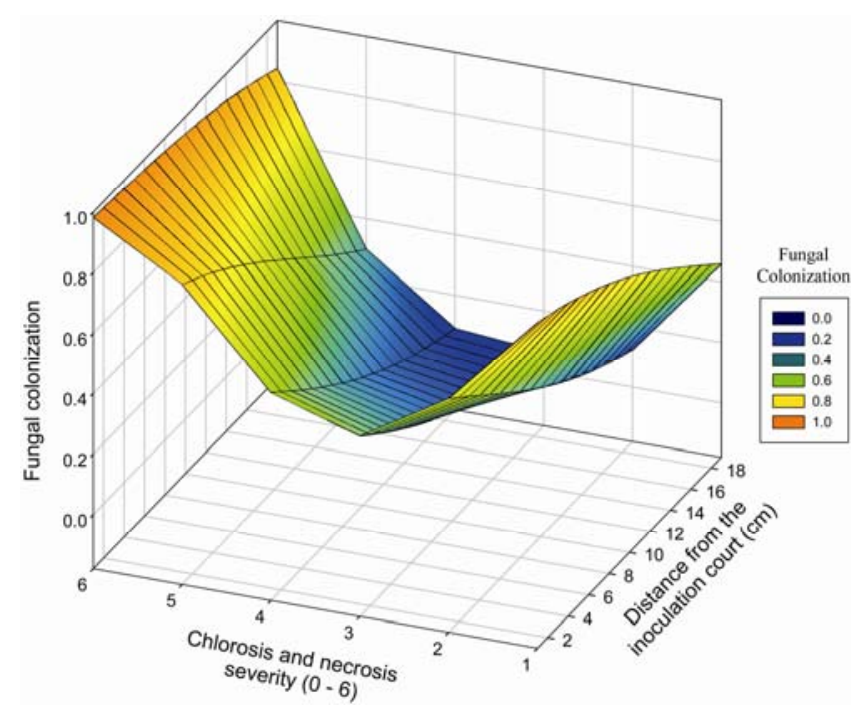

Fig. 3. Relationship among fungal colonization of the lower stem section, chlorosis and necrosis severity, and distance from the inoculation court in potato plants infected with Colletotrichum coccodes isolates 1018 and 2044 in 2003.

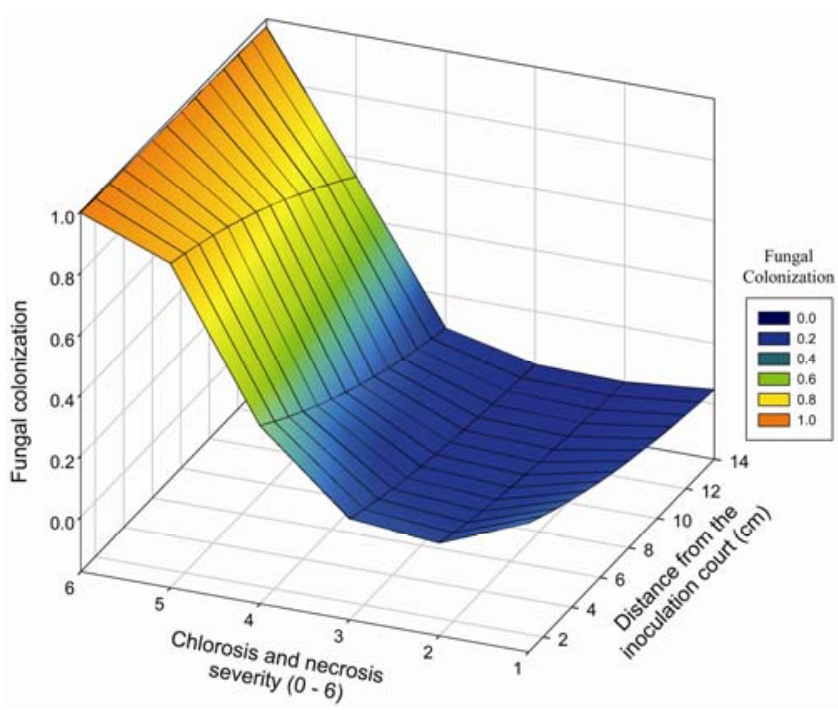

Fig. 4. Relationship among fungal colonization of the lower stem section, chlorosis and necrosis severity, and distance from the inoculation court in potato plants infected with Colletotrichum coccodes isolates 1018 and 2044 in 2004. 
(Fig. 2) was restricted between 0.0 and 0.2 as chlorosis and necrosis severity developed from category 1 to 3 . Similar to the results of 2003, fungal colonization in 2004 increased from 0.2 to 0.9 (Fig. 2) as the severity of chlorosis and necrosis exceeded category 3 .

On the lower stem sections, fungal colonization was similar to that of the upper stem sections. Fungal colonization was restricted until the severity of chlorosis and necrosis exceeded category 3 (plant senescence), after which it greatly increased (Figs. 3 and 4). In contrast to the upper stem sections, colonization of the lower stem sections did not decrease as quickly as distance from the inoculation court increased (Figs. 1 to 4 ).

\section{DISCUSSION}

The similar development of chlorosis and necrosis severity on infected and noninfected control plants (Fig. 5) pointed to the probable hypothesis that natural senescence was the cause of chlorosis and necrosis and not the infection and colonization of the plants by $C$. coccodes. The curvilinear relationship between fungal colonization and chlorosis and necrosis severity pointed to another probable hypothesis that natural senescence significantly affected $C$. coccodes growth and colonization of potato plants. The restricted colonization of plant stems by $C$. coccodes indicated a latency period that was overcome as the potato plants started to senesce. $C$. coccodes colonization was then activated, probably by physiological events associated with plant senescence that took place in the Russet Burbank potato plants between 95 and 105 days after planting. Comparisons between growth stages of potato plants grown in the greenhouse and in the field should only be made for relative purposes. With this in mind, at 100 days after planting, long-season potatoes, such as Russet Burbank, in the Columbia Basin of Washington State are generally starting the last half of the linear bulking in growth stage 4 (31). During this period, which generally ends at 120 to 130 days after planting, the vegetative growth stops, sugars are translocated to the maturing tubers, and plants start to senesce.

The relationship between $C$. coccodes and plants' senescence has been previously reported in potato and tomato plants $(7,18)$. Mohan et al. $(18)$ noted the lack of foliar symptoms on inoculated potato plants in the field until senescence. Dillard and Cobb (7) demonstrated that isolation of $C$. coccodes from infected plants increased as tomato fruit matured, and Last and Ebben (16) reported a rapid increase in black dot symptoms in tomato roots toward the end of the season. In addition, latent infections in various hosts have been observed for Colletotrichum spp. Infection of $C$. coccodes in tomato fruit and of $C$. piperatum and $C$. gloeosporioides in pepper, mango, and avocado demonstrated latency prior to fruit ripening and a break of latency when fruit ripened $(3,7,16,22-$ 24,30).

Plant hormones such as ethylene and jasmonic acid are reported to be involved in the regulation of many diverse aspects of plant development, including organ senescence $(10,15,25)$ and the development of potato tubers (27). Ethylene has also been reported to induce germination and appressorium formation of Colletotrichum species (9). The role of plant hormones in black dot development has never been studied. However, it is possible that the increased endogenous levels of ethylene and/or jasmonic acid as plants senesce and/or potato tubers mature and enlarge is the cue that activates $C$. coccodes growth and colonization.

The insignificant quadratic coefficient in 2004 caused the regression surface to have a more linear pattern than in 2003. The difference was most evident as chlorosis and necrosis severity progressed from category 1 to 3 . This difference may be either the result of a variation in temperatures $\left(19 \pm 5.1^{\circ} \mathrm{C}\right.$ and $23 \pm 3.4^{\circ} \mathrm{C}$ in 2003 and 2004 , respectively) or due to photoperiod. The 2003 trial was conducted during the fall (short days), whereas the 2004 trial was conducted during the spring (long days). C. coccodes and consequentially black dot development has been reported to be affected by day length $(28,29)$, which may explain the observed differences in the regression surface between the two years.

Based upon the findings of the present study, we hypothesize the following model of stem colonization after aerial infection by $C$. coccodes in potato. C. coccodes may be distributed on leaves and stems of potato and with moisture, spores, and/or scle-

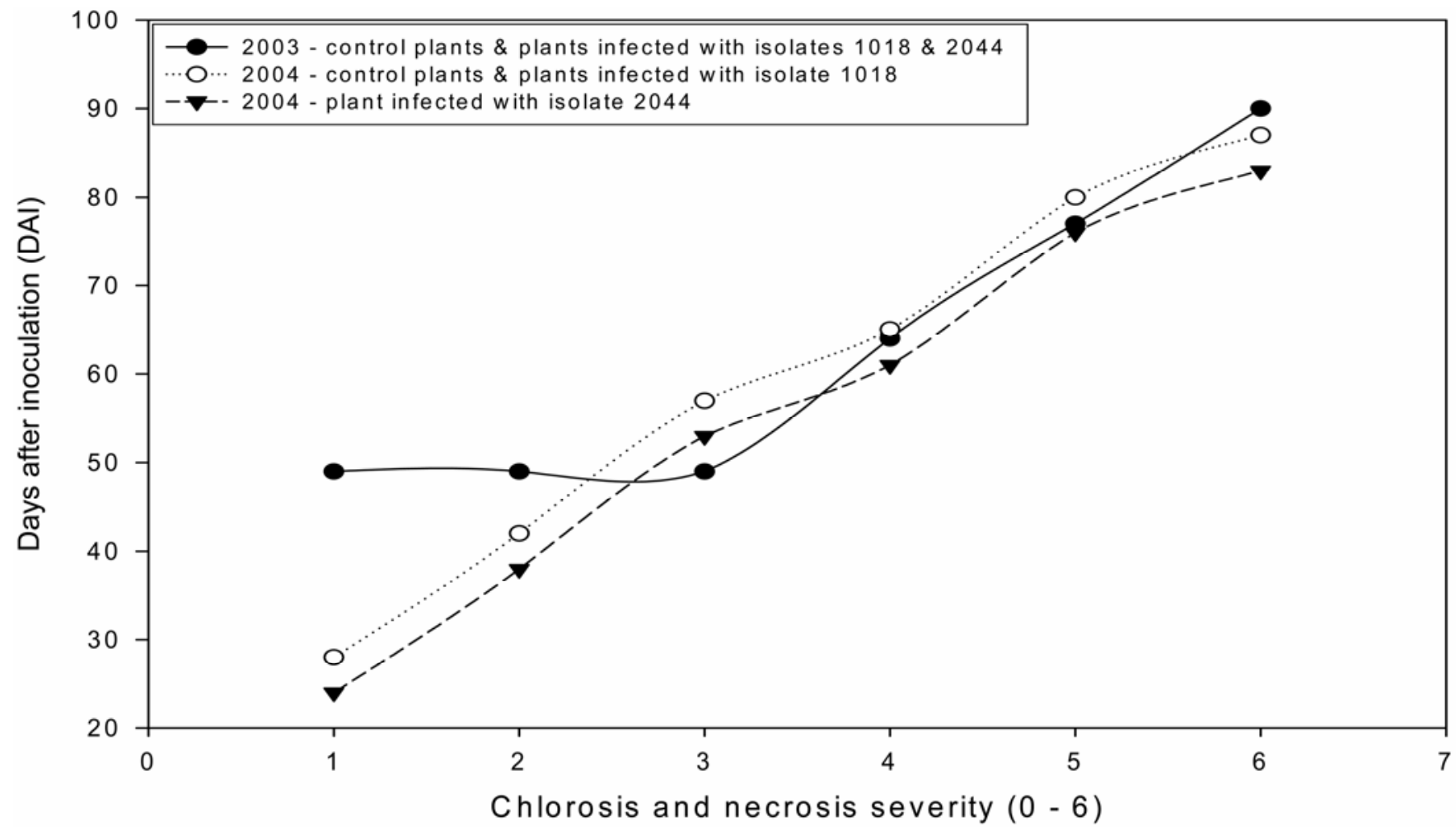

Fig. 5. Development of chlorosis and necrosis severity on potato plants that were either infected or noninfected with Colletotrichum coccodes isolates 1018 and 2044 in 2003 and 2004 in the greenhouse. 
rotia germinate and the pathogen infects the host. Sandstorms and water from irrigation promote this process $(12,13)$. Infection becomes latent until plants enter growth stage 4 , in which tubers bulk and plants start to senesce. Increased levels of endogenous ethylene and/or jasmonic acid may be the cue that activates fungal growth and colonization $(10,15,25,27)$. Latent infection and activation of fungal growth in association with plant senescence may also occur in the presence of soil-borne and/or tuber-borne inocula.

The study suggests that $C$. coccodes infection of potato plants is latent, and that physiological processes in the plants, which are associated with plant senescence, activate $C$. coccodes growth. The results of the present study show no relationship between plant colonization by $C$. coccodes and the severity of chlorosis and necrosis of leaves (Fig. 5). Chlorosis and necrosis severity was found to be an inaccurate tool to diagnose infection in potato by $C$. coccodes, and therefore did not indicate the presence or amount of $C$. coccodes in potato plants. Disease symptoms of black dot in previous field studies have been noted not to appear or to be confused with those caused by Verticillium dahliae or natural senescence $(14,18,28)$. The lack of specific disease symptoms on potato foliage due to $C$. coccodes has made detection of the disease and the development of control practices for black dot difficult. Because black dot symptoms are not readily evident on foliage, other methods of disease and pathogen detection are needed, such as examination of roots for cortical rot, and isolation and quantification of the fungus from stems and roots using CFU/g of fresh weight or polymerize chain reaction techniques. Assessment for C. coccodes in potato should begin before plant senescence and likely much earlier. Furthermore, contact fungicides applied after initial infections are not likely to effectively reduce disease severity because of latent infection and internal expansion of C. coccodes in potato stems. Therefore, systemic fungicides, host resistance, crop rotations, and other disease management practices may be needed to achieve economic control of potato black dot.

\section{ACKNOWLEDGMENTS}

We thank the Washington State potato commission for supporting this research. The following manuscript was assigned Plant Pathology new series no. 0409, Department of Plant Pathology, College of Agricultural, Human, and Natural Resource Sciences Research Center, Project No. 0678, Washington State University, Pullman, WA 991646430, USA.

\section{LITERATURE CITED}

1. Andrivon, D., Ramage, K., Guerin, C., Lucas, J. M., and Jouan, B. 1997. Distribution and fungicide sensitivity of Colletotrichum coccodes in French potato-producing areas. Plant Pathol. 46:722-728.

2. Barkdoll, A. W., and Davis, J. R. 1992. Distribution of Colletotrichum coccodes in Idaho and variation in pathogenicity on potato. Plant Dis. 76:131-135.

3. Byrne, J. M., Hausbeck, M. K., Meloche, C., and Jarosz, A. M. 1998. Influence of dew period and temperature on foliar infection of greenhouse-grown tomato by Colletotrichum coccodes. Plant Dis. 82:639-641.

4. Chesters, C. G. C., and Hornby, D. 1965. Studies on Colletotrichum coccodes. I. The taxonomic significance of variation in isolates from tomato roots. Trans. Br. Mycol. Soc. 48:573-581.

5. Denner, F. D. N., Millard, C., Geldenhuys, A., and Wehner, F. C. 1997. Treatment of seed potatoes with Prochloraz for simultaneous control of silver scurf and black dot on progeny tubers. Potato Res. 40:221-227.

6. Denner, F. D. N., Millard, C. P., and Wehner, F. C. 1998. The effect of seed- and soil-borne inoculum of Colletotrichum coccodes on the incidence of black dot on potato. Potato Res. 41:51-56.

7. Dillard, H. R., and Cobb, A. C. 1997. Disease progress of black dot on tomato roots and reduction in incidence with foliar applied fungicides. Plant Dis. 81:1439-1442.

8. Dillard, H. R., and Cobb, A. C. 1998. Survival of Colletotrichum coccodes in infected tomato tissue and in soil. Plant Dis. 82:235-238.

9. Flaishman, M. A., and Kolattukudy, P. E. 1994. Timing of fungal invasion using host's ripening hormone as a signal. Proc. Natl. Acad. Sci. 91:6579-6583.

10. He, Y., Fukushige, H., Hildebrand, D. F., and Gan, S. 2002. Evidence supporting a role of jasmonic acid in Arabidopsis leaf senescence. Plant Physiol. 128(3):876-884.

11. Hosmer, D. W., and Lamashow, S. 1989. Applied Logistic Regression. John Wiley \& Sons, New York.

12. Johnson, D. A. 1994. Effect of foliar infection caused by Colletotrichum coccodes on yield of Russet Burbank potato. Plant Dis. 78:10751078.

13. Johnson, D. A., and Miliczky, E. R. 1993. Effects of wounding and wetting duration on infection of potato foliage by Colletotrichum coccodes. Plant Dis. 77:13-17.

14. Johnson, D. A., Rowe, R. C., and Cummings, T. F. 1997. Incidence of Colletotrichum coccodes in certified potato seed tubers planted in Washington State. Plant Dis. 81:1199-1202.

15. Kuo Tung Hung and Ching Huei Kao. 1997. Senescence of rice leaves XXXV. Promotive effects of jasmonites. Bot. Bull. Acad. Sinica 38:85-89.
16. Last, F. T., and Ebben, M. H. 1966. The epidemiology of tomato brown root rot. Ann. Appl. Biol. 57:95-112.

17. Lees, A. K., and Hilton, A. J. 2003. Black dot (Colletotrichum coccodes): An increasingly important disease of potato. Plant Pathol. 52:312.

18. Mohan, S. K., Davis, J. R., Sorensen, L. H., and Schneider, A. T. 1992. Infection of aerial parts of potato plants by Colletotrichum coccodes and its effects on premature vine death and yield. Am. Potato J. 69:547-559.

19. Nitzan, N. 2005. Epidemiology, etiology and population structure of Colletotrichum $\mathrm{coc}$ codes, the causal agent of potato black-dot in North America. Ph.D. diss. Washington State University, Pullman. Chapter 1:7-31.

20. Nitzan, N., Hazanovsky, M., Tal, M., and Tsror (Lahkim), L. 2002. Vegetative compatibility groups in Colletotrichum coccodes, the causa agent of black dot on potato. Phytopathology 92:827-832.

21. Nitzan, N., and Tsror (Lahkim), L. 2003. Effect of temperature and $\mathrm{pH}$ on in vitro growth rate and sclerotial density of Colletotrichum coccodes isolates from different VCGs. Am. J. Potato Res. 80:335-339.

22. Prusky, D., Ascarelli, A., and Jacoby, B. 1984. Lack of involvement of nutrients in the latency of Colletotrichum gloeosporioides in unripe avocado fruits. Phytopathol. Z. 110:106-109.

23. Prusky, D., Keen, N. T., and Eaks, I. 1983. Further evidence for the involvement of a preformed antifungal compound in the latency of Colletotrichum gloeosporioides on unripe avocado fruit. Physiol. Plant Pathol. 22:189-198.

24. Prusky, D., Kobiler, I., Jacoby, B., Sims, J. J., and Midland, S. L. 1985. Inhibitors of avocado lipoxygenase: Their possible relationship with the latency of Colletotrichum gloeosporioides. Physiol. Plant Pathol. 27:269-279.

25. Reid, M. S. 1995. Ethylene in plant growth, development, and senescence. Pages 486-508 in: Plant Hormones: Physiology, Biochemistry, and Molecular Biology, Ed 2. P. J. Davies, ed. Kluwer Academic Publishers, Dordrecht, The Netherlands.

26. Stevenson, W. R., Green, R. J., and Bergesen, G. B. 1976. Occurrence and control of black dot root rot in Indiana. Plant Dis. Rep. 60:248 251.

27. Suttle, J. C. 1998. Involvement of ethylene in potato microtuber dormancy. Plant Physiol. 118:843-848.

28. Tsror (Lahkim), L. 2004. Effect of light duration on severity of black dot caused by Colletotrichum coccodes on potato. Plant Pathology 53:288-293.

29. Tsror (Lahkim), L., Erlich, O., and Hazanovsky, M. 1999. Effect of Colletotrichum coccodes on potato yield, tuber quality, and stem colonization during spring and autumn. Plant Dis. 83:561-565.

30. Wall, M. M., and Biles, C. L. 1993. Alternaria fruit rot of ripening chile peppers. Phytopathology 83:324-328.

31. Westermann, D. T. 1993. Fertility and management. Chapter 9, page 78 in: Potato Health Management. R. C. Rowe, ed. American Phytopathological Society, St. Paul, MN. 